\title{
Abstract Lexical Structure and Language Transfer in Second Language Learning
}

\author{
Xuexin Liu \\ Spelman College \\ 350 Spelman Lane SW, Atlanta \\ Georgia 30314, USA \\ Longxing Wei \\ Montclair State University \\ 1 Normal Avenue, Montclair \\ New Jersey 07043, USA
}

\begin{abstract}
This study adopts the Bilingual Lemma Activation Model (BLAM) to investigate the sources of language transfer and the linguistic nature of interlanguage (IL). The BLAM assumes that the bilingual mental lexicon contains abstract elements called 'lemmas' underlying lexemes and that abstract lexical structure contains three levels: lexical-conceptual structure, predicate-argument structure, and morphological realization patterns. This study provides evidence in support of the BLAM's claim that language-specific lemmas in contact in the bilingual mental lexicon and first language (L1) abstract lexical structure may influence second language (L2) learning and affects IL development. The typical language transfer instances from the IL production of adult native speakers of Japanese learning English as an L2 and adult native speakers of English learning Japanese as an L2. Based on the findings, this study concludes that language transfer should be viewed as lemma transfer during the activation of L1 knowledge at each level of abstract lexical structure.
\end{abstract}

Keywords: language transfer, influence, abstract lexical structure, lemma, bilingual, mental lexicon, interlanguage

\section{Introduction}

This study reviews some earlier models of Second Language Acquisition (SLA) and their assumptions about the nature and tole of language transfer in L2 learning (the term 'L2 learning' here covers any foreign language learning)and discusses some potential weaknesses of each. These models to be critically reviewed include Contrastive Analysis (CA) (Weinreich, 1953; Lado, 1957; Wardhaugh, 1970), Error Analysis (EA) (Corder, 1967; Richards, 1974), IL theory (Selinker, 1972), and Universal Grammar (UG) (Chomsky, 1965; Bickerton, 1981; Pinker, 1984; Krashen, 1985; White, 1990; Cook, 1991). To introduce the BLAM(Wei, 2002, 2015) to be applied to the investigation of language transfer in L2 learning presented in this study, some recent models are reviewed as a theoretical background, which include the Competition Model (CM) (MacWhinney, 1987) the psycholinguistic model of L2 vocabulary acquisition (Jiang, 2000), and the Modified Hierarchical Model (MHM) (Pavlenko, 2009).

As to be reviewed, most previous models of SLA make assumptions about the learner errors or language transfer at the observational or descriptive level without exploring learners' mental activity in the process in L2 learning. The BLAM, one of the most recent psycholinguistic models, draws on some insights of some recent models of SLA but aims to explore the nature and activity of the bilingual mental lexicon at a rather deeper or more abstract level. This model is 'abstract' in the sense that lexical structure contains three abstract levels: lexical-conceptual structure, predicate-argument structure, and morphological realization patterns, and the mental lexicon contains abstract elements called 'lemmas', which provide information about lexemes realized at each of these three levels. The crucial assumption underlying this model is that the lemmas contained in the bilingual mental lexicon are languagespecific and are in contact in L2 learning.

This study adopts the BLAM to describe and explain sources of language transfer in L2 learning by assuming that language transfer is an avoidable consequence of bilingual systems (i.e., bilingual lemmas) in contact during IL development. The typical instances of language transfer for the study are from adult native speakers of American English learning Japanese as an L2 in college classroom settings. Three types of language transfer are discussed: word choices at the level of lexical-conceptual structure, grammatical constructions at the level of predicateargument structure, and surface devices at the level of morphological realization patterns. This study concludes that the developing linguistic system of IL should be understood as a composite containing several linguistic sources such as learners' L1, certain incompletely acquired TL items, and some completely acquired TL items, each of which contributes different amounts to the developing system along the IL continuum. 


\section{Models of Language Transfer and Theories of Second Language Acquisition}

One of the major issues in SLA research is the nature and role of language transfer in L2 learning. Some earlier outstanding models of language transfer include CA, EA, IL theory, and UG. Some recent models of language transfer include the Competition Model (CM), the MHM, the psycholinguistic model of L2 vocabulary learning, and the BLAM.

\subsection{CA and Its Weaknesses}

CA (Weinreich, 1953; Lado, 1957; Wardhaugh, 1970), for pedagogical purposes, describes the structural differences and similarities of two or more languages, and it has been influential through the Contrastive Analysis Hypothesis $(\mathrm{CAH})$ claiming that it is the differences between the L2 and learners' L1 which cause learning difficulties and learner errors. "The greater the difference between two systems, i.e., the more numerous the mutually exclusive forms and patterns in each, the greater is the learning problem and the potential area of interference (Weinreich, 1953, p. 1). "Individuals tend to transfer the forms and meanings and the distribution of forms and meanings of their native language and culture to the foreign language and culture," and "those elements that are similar to his native language will be simple for him, and those elements that are different will be difficult" (Lado, 1957, p. 2). Accordingly, Wardhaugh (1970) proposes the CAH: "Where two language were similar, positive transfer would occur; where they were different, negative transfer, or interference, would result" (LarsenFreeman \& Long, 1991, p. 53). Thus, CAH claims that difficulties in L2 learning derive from the differences between the L2 and learners' L1, that errors in the areas of difference derive from L1 interference and that these errors can be predicated and remedied by the use of CA.

CA has several weaknesses. The first is its inability to predict learner errors. Dulay and Burt (1974), Ervin-Tripp (1974), Selinker, Swain, and Dumas (1975), Hyltenstam (1977), Zobl (1980a, 1980b), and Dušková (1984) provide typical examples as evidence that CA fails to predict what is actually occurring in L2 learners' error production. The second is its hypothesis that language consists of a set of automatic habits and language learning is an imitation of such habits. McNeil (1966), Cazden (1972), and Gass and Selinker (1994), among many others, provide typical examples as evidence that against CA's behaviorist theory of language learning. The third is its hypothesis that difference signifies difficulty and difficulty induces errors. Kellerman (1987) provides typical examples as evidence against such a hypothesis and questions the equation of difference with difficulty. "To equate difference with difficulty attributes a psycholinguistic explanation to a linguistic description. It is a confusion of the product (a linguist's description) with the process (a learner's struggle with the second language)" (Gass \& Selinker, 1994, p. 64).

\subsection{EA and Its Weaknesses}

Different from CA, EA focuses on learner errors and makes a comparison between learner errors in producing the TL and the TL forms themselves, rather than between learners' L1 and the TL to catch differences. According to Corder $(1967,1971)$, learner errors are 'significant' because they reflect the state of learners' current knowledge of the TL and provide evidence of an underlying rule-governed developing linguistic system, rather than the consequence of faulty imitation. In other words, EA views learner errors from the perspective of the TL only. Thus, learner errors are recognized with reference to some norm of the TL. Within the framework of EA, Richards (1974) identifies interlingual vs. intralingual learner errors. Learner errors are identified as interlingual if they can be attributed to learners' L1, and learner errors are identified as intralingual if they can be attributed to the TL itself. In other words, interlingual learner errors are caused by L1 interference, but intralingual learner errors are caused by degrees of learning difficulty of the TL.

EA also has several weaknesses. The first is that it presents a very incomplete picture of SLA because it only focuses on part of the TL that learners produce which makes it difficult to understand learners' developmental sequence. The second is that considerable problems appear when learner errors are categorized as intralingual errors (i.e., developmental errors) or interlingual errors (i.e., L1 interference). The third is that it only focuses on learner errors without viewing the whole picture or the process of SLA. The fourth is that it fails to explore sources of learner errors and thus cannot account for all the areas of learning difficulty which may cause interlingual or intralingual learner errors. Schachter (1974), Kleinmann (1977), Dagut and Laufer (1985), and Ellis (1994) provide evidence that learners may avoid certain TL items in order not to create errors (i.e., certain interlingual errors can be avoided), and that there are specific cases that EA cannot identify as apparent areas of learning difficulty (i.e., certain intralingual errors cannot be identified).

\subsection{IL Theory and Its Weaknesses}

IL refers to a particular and systematic knowledge of language which is not identical to either learners' NL system or the TL system being learned in a certain stage (Nemser, 1971; Selinker, 1972). IL theory claims that learner errors are systematic in the sense that they are learners' own particular version of the TL based on some systematic knowledge of the TL being learned in a certain stage or personal competence. 
In other words, learners must possess their 'personal' grammars to construct their utterances. The term 'IL' implicates that learners' language system will show systematic features of both the TL and other languages they know, most obviously their NL. The term 'IL' also implicates two related but different notions: the developing linguistic system constructed by learners in a certain stage (i.e., IL system), and the series of interlocking systems (i.e., IL continuum).

The earlier IL theory is fundamental different from CA and EA but also has some weaknesses. The first is that without exploring the origin of IL, it would be impossible to describe and explain how learners build up and revise the interim system by gradually increasing the complexity of the IL system. If learners start from "some basic simple grammar" (Corder, 1981, p. 150), is this "simple grammar" the only source of the sentential frame for IL utterances? The second is that it ignores the relationship between the input and learners' internal processing mechanisms. Thus, it becomes necessary to consider certain cognitive aspects and linguistic mechanisms of language processing and production as revealed by learners moving along the IL continuum (Myers-Scotton \& Jake, 1994; Jake, 1994; Wei, 1996a, 2000a, 2000b; Liu, 2015, Liu \& Wei, 2017). The third is that it does not pay much attention to language transfer in L2 learning, and it does not clearly define or largely ignores the relationship between learners' L1 and their IL and the relationship between their IL and the TL. According to Klein and Perdue (1989), Jake (1994, 1998), and Wei (1996a, 1996b), in different stages, L1 influence or interference may apparently affect the developing IL to different degrees due to learners' limited knowledge of the TL morphosyntactic rules, and thus certain TL items, whether lexical, grammatical or morphological, are incompletely acquired in a particular stage.

\subsection{UG Theory and Its Weaknesses}

UG is a linguistic theory originally proposed by Chomsky $(1965,1980,1981)$ to solve the logical problem of language acquisition. It aims to identify linguistic universals through the in-depth study of a single language.Its most crucial claim is that all learners follow a universal route because they possess a tacit knowledge of grammar, which is triggered by a natural language environment. That is, natural language acquisition is governed by a set of universal principles possessed by humans as their language faculty (i.e., natural language endowment or innate language acquisition device). The researchers applying UG theory to SLA research (e.g., Krashen, 1982; White, 1990; Cook, 1991, among others) claim that the UG principles and parameters may still be activated in adult L2 learning in the same way as in child L1 acquisition. Such researchers claim that adult L2 learners have access to UG and their errors are not predominantly the consequence of language transfer or L1 interference. According to Cook (1985, 1988), White (1985a, 1985b, 1987) and Flynn (1987), a given language will trigger a particular parameter in one way, whereas another language will trigger a particular parameter in another way.

UG, as a theory of natural language acquisition, also has some obvious weaknesses when applied to SLA research. The first is that it advocates a similar language acquisition process for both L1 and L2 learners without recognizing that L1 interference may interact with universal learning principles and strategies. That is, such a theory fails to explain why L2 learners with particular L1 backgrounds tend to make certain particular learner errors or overgeneralizations, and why such learner errors or overgeneralizations are not observed in L1 acquisition. The second is that the role of UG in SLA is questionable. Schachter (1988) and Bley-Vroman (1989) claim that L1 acquisition and L2 acquisition cannot be the same because the differences between them are apparently revealed in difference in success, fossilization, nature of intuition, relevance of instruction, previous knowledge and the like. The third is that there is no consistent evidence that L2 learners are capable of switching form one parameter to another or shifting parameter values. Thus, it becomes doubtful whether parameter resetting is a determinant mechanism in SLA.

Beyond the earlier models of language transfer, some recent models have advanced this particular field of study, such as the CM and the MHM. The BLAM draws on some insights of these models.

\subsection{The CM of Bilingual Processing}

From a functionalist and connectionist point of view, and departing from the UG principles and parameters, the CM attributes L1 and L2 development to learning and transfer (MacWhinney, 1987, 1989, 1992, 1996, 1997). Most relevant to the issues of language transfer is the CM's claim that learners' L1 and L2 differ in their degree of processing independence. It further claims that bilingual processing involves 'competition' between the two languages in every level of processing, and it is the stronger 'cues' of one language's lexicon, phonology or grammar what win the competition. In other words, L2 learning involves bilingual processing and languagespecific cues are in competition. This predicts that early L2 learners will transfer all aspects of their L1 that can be transferred because their L1 cues are obviously stronger than the equivalent L2 cues.

According to the CM, it is learners' parasitic L2 lexicon, phonology or grammar which unavoidably causes language transfer before the relevant L2 cues become strengthened and strong enough to win the competition. 
Though such a prediction is highly falsifiable, the BLAM draws on the notion of 'competition' based on relative cue strength, cue summation and interactive activation to explore the nature and activity of the bilingual mental lexicon in relation to language transfer in L2 learning.

\subsection{The MHM of Bilingual Conceptual Representations}

To explore cross-linguistic differences at the level of conceptual representation in the bilingual lexicon, The MHM assumes that bilingual "conceptual representations may be fully shared, partially overlapping or fully languagespecific" (Pavlenko, 2009, p. 146). Many studies in bilingualism have provided evidence that the same bilingual speakers may perform some tasks under language-specific constraints and display certain language transfer (Green, 1998; Pavlenko, 1997, 2003; Jarvis, 2003, 2009; Barsalou, 2003; Malt, Sloman, \& Gennari, 2003; Costa, 2005; Stepanova Sachs \& Coley, 2006; Wei, 2015, 2017). The MHM further assumes that language-specific lexical concepts (i.e., semantic representation) may cause conceptual transfer. Pavlenko differentiates "between errors made at the level of linking (semantic transfer) and those that involve the structure of conceptual categories (conceptual transfer)" (2009, p. 148).

The MHM claims that it is he degree of cross-linguistic conceptual equivalence (i.e., equivalence, partial (non)equivalence or non-equivalence) that causes different amounts of language transfer in L2 vocabulary learning and that "conceptual restructuring" becomes crucial in shaping bilinguals' conceptual representations as affected by the distinct conceptual equivalence relationship between languages (Pavlenko, 2009, p. 153).

The BLAM draws on the MHM's notion of language-specific lexical concepts and its notion of degree of crosslinguistic conceptual equivalence to explore the nature and activity of the bilingual mental lexicon in language transfer at the abstract level of lexical-conceptual structure. It adopts a more general term 'lexical-conceptual transfer' to include bilinguals' lexical vs. conceptual representations as revealed in learner errors.

\subsection{The BLAM of Language Transfer}

From some psycholinguistic perspectives, the BLAM aims to identify sources of abstract lexical structure in the bilingual mental lexicon in relation to IL development in general and language transfer in particular (cf. Talmy, 1985; Pinker, 1989a, 1989b; Levelt, 1989; Jackendoff, 1990; Bock \& Levelt, 1994; Myers-Scotton \& Jake, 1995; Jake, 1998; Fuller, 1999; Wei, 2001, 2002, 2003; Liu, 2015; Wei\&Liu,2017). It makes four assumptions about the nature and activity of the bilingual mental lexicon in L2 learning:

The first is the assumption that the mental lexicon does not simple contain lexemes but abstract elements called 'lemmas', which are abstract entries (i.e., pieces of information) about a particular lexeme.The BLAM argues that lexemes may be shared among languages, but lemmas are language-specific in the bilingual mental lexicon, and language-specific lemmas are in contact in IL production. The second is the assumption that lexical structure is 'abstract' in the sense that it contains several discrete but interacting subsystems, such as lexical-conceptual structure, predicate-argument structure, and morphological realization patterns, each of which is a particular component of grammar. The BLAM argues that abstract lexical structure in the developing IL system may have different sources at different levels of L2 learning. The third is the assumption that language transfer or L2 influence in IL construction is transfer of abstract lexical structure at each of these subsystems. The BLAM argues that such a transfer becomes indispensable and necessary for learners to fill particular gaps in the incompletely acquire TL items. The fourth is the assumption that abstract lexical structure is modular and can be split and recombined in novel, yet constrained ways in constructing the developing IL system. The BLAM argues that parts of the abstract lexical structure from learners' L1 lexical entries (i.e., lemmas) may influence the abstract lexical structure of incompletely acquired TL lexical entries in IL production.

\section{Abstract Lexical Structure in Language Transfer}

The BLAM proposes that the abstract lexical structure of IL is a composite and has several implications for IL construction. This is because L1 lexical structure may fill gaps at each of the three abstract levels: lexicalconceptual structure, predicate-argument structure, and morphological realization patterns. When this happens, language transfer or learner errors will result in IL construction. Below are some typical instances of L1 transfer in each of these abstract levels as performed by the adult native speakers of Japanese learning English as an L2 and adult native speakers of American English learning Japanese as an L2.

\subsection{Transfer of L1 Lexical-Conceptual Structure in IL Construction}

The first level or subsystem of abstract lexical structure is called 'lexical-conceptual structure'. Linguists like Talmy (1985), Levelt (1989), Jackendoff (1991), Levin and Pinker (1991), Bierwisch and Schreuder (1992), Jake (1998), and Wei (1998) hold that different languages may lexicalize certain components of a given conceptual structure in different ways because the lexical-conceptual structure of a lexeme in a particular language contains a specific bundle of semantic/pragmatic features. In other words, there are cross-linguistic variations in the semantic/pragmatic features of certain lexemes. Researchers like Zughoul (1991), Lennon (1991), Biskup (1992, 
Jiang (2000), and Wei (2006a, 2006b) find that learners' IL lexemes may contain semantic/pragmatic features from their L1 counterparts. This is because learners' L2 lexical items may be partial or incomplete in terms of their semantic/pragmatic information (also, their syntactic and/or morphological information) during IL development. Such a partial or incomplete L2 lexicon is recognized as 'IL lexicon'. As predicted and evidenced in many studies in SLA, learners may activate equivalent seemingly equivalent lexical items from their L1 in their IL production when their incompletely acquired L2 lexical items are insufficient for them to express their intended meanings (for specific examples of lexical transfer, see Dewaele (1998), Jake (1998), Jiang (2000), Liu (2012), Wei and Liu (2017), and Wei (2006a, 2006b, 2015)).

As introduced earlier, lemmas underlying lexemes are language-specific in the bilingual mental lexicon, and though languages may share lexemes, the lemmas underlying certain lexemes may differ. Thus, the lexical-conceptual structure driven by L1 lemmas can be activated to meet L2 learners' communicative needs before they completely acquire certain L2 lexical items, resulting in the transfer of L1 lexical-conceptual structure in IL construction (i.e., inappropriate lexical choices). To be more accurate, to completely acquire any L2 lexical item means to completely acquire all the lemmas about its lexical-conceptual structure. Below are some typical instances of transfer of L1 lexical-conceptual structure in IL construction.

[1] I study English for work in Japanese. My parent want do me teacher ... teach English in Japan.

[2] Yesterday in library I look Japanese magazine.

(Japanese L1; Wei, 1996a, p. 423)

[3] He is funny. His words in class laugh me. (Japanese L1, Wei, 1995)

[4] My husband doesn't wash ... never wash the dishes.

[5] When I'm sick, when I've cold I eat medicine, cold medicine.

[6] In Japan all students do English study in school.

[7] In Japan students do many test and exams in class.

(Japanese L1; Wei, 2003, p. 65)

In [1], $d o$ in Japanese has multiple semantic features, such as 'make' and also 'try, act, play'. The speaker uses the English verb doto express the meaning of 'make' in Japanese. In [2], look in Japanese has multiple semantic features, such as 'read' and also 'see, look at, visit, observe'. The speaker uses the English verb look to express the meaning of 'read'. In [3], the speaker activates the lemmas for the Japanese causative lexical-conceptual structure, where his words can be the 'causer'. In English the 'causer' must be the AGENT (I), and his words should be a prepositional stimulus (at his words): (e.g., 'I laugh at his words'). In this instance, the resulting causative lexicalconceptual structure affects the predicate-argument structure and its morphological realization patterns. In [4], the speaker uses wash instead of do (e.g., 'do the dishes') because of the Japanese lemmas for wash. In [5], the speaker uses eat instead of take (take medicine) because of the Japanese lemmas for eat. In [6], the speaker activates the Japanese lemmas for the lexical-conceptual structure of study introduced by the verb do and the noun expressing the activity in question. In [7], the speaker activates the Japanese lemmas for 'do' in saying do many tests and exams instead of 'take' (e.g., 'take many tests and exams').

[8] watashi wa mai nichi juuni ji ni hirugohan ga aru.

I PART/TOP everyday 12 o'clock PART/NOM have

"I have lunch at 12 o'clock everyday."

[9] haha was shokuji no atode shokki o suru.

mother PART/TOP meal PART/POSS after dish PART/OBJ do

"(My) mother does the dishes after the meal."

[10] kare wa shaken o toru.

he PART/TOP test PART/OBJ take

"He will take the test."

[11] watashi wa tenisu o asobu.

I PART/TOP tennis PART/OBJ play

"I pay tennis."

(English L1; Wei, 2003, p. 65)

In [8], the speaker activates the English lemmas for 'have (aru)' as in 'have lunch' rather than the Japanese equivalent verb 'taberu (eat)' for the same concept. In [9], the speaker activates the lemmas for 'do (suru)' as in 'do the dishes' rather than the Japanese equivalent verb 'arau (wash)' for the same concept. In [10], the speaker produces the verb 'toru (take)' instead of 'ukeru (receive)' to realize the equivalent expression 'take the test'. In [11], the speaker produces the verb 'asobu (play)' based on the English lemmas for the verb as in 'play tennis' rather than the Japanese verb 'suru (do)' as used in combination with other nouns to express a particular activity. 
The above instances reveal that the lexical-conceptual structure, as one of the subsystems, of the TL abstract lexical structure is not available to early-stage learners. Although learners produce the TL lexical items, their choice of those items may be cause or interfered by their incomplete knowledge of the TL lexical-conceptual of particular lexemes. As predicted by the BLAM, when bilingual lemmas are in contact, language-specific lemmas for the universal concepts based on learners' L1 may activate or the TL lexical items in an inappropriate manner. It this happens, L1 lexical-conceptual structure may appear in IL construction. Thus, early-stage learners' use of L2 lexical items tends to be influenced or even interfered by the L1 lemma activation in the bilingual mental lexicon.

\subsection{Transfer of L1 Predicate-Argument Structure in IL Construction}

The second level or subsystem of abstract lexical structure is called 'predicate-argument structure', which is defined as the number of arguments (i.e., lexical nouns) required by the verb and a particular thematic role assigned by the verb. For example, the transitive verb 'eat' requires two arguments, and it assigns the thematic role of AGENT to the noun which must be able to perform the act of eating and the thematic role of THEME to the noun which must be something edible. If the verb 'eat' is intransitive, it requires only one argument to the noun which must be assigned the thematic role of AGENT. In other words, each verb determines the number of arguments (i.e., nouns) and a particular thematic role assigned to each argument. Thus, in order for any verb to be used 'grammatically' and 'meaningfully', both the number of argument(s) and their related thematic role(s) must be satisfied. The information about any verb's predicate-argument structure is contained in the lemmas for that verb.

As revealed in the researches by Fuller (1999), Wei(2004, 2006a, 2018), Liu (2015, 2019), Wei and Liu (2017)among others, because of their incomplete knowledge of certain L2 lexical items, to be more specific, the lemmas underlying these L2 lexical items, learners may choose the right verbs without knowing the lemmas for these verbs and use them incorrectly, resulting in the transfer of L1 predicate-argument structure in IL construction (i.e., ungrammatical sentences). To be more accurate, to completely acquire any L2 lexical item also means to completely acquire the lemmas about its predicate-argument structure.

[12] I can wait you here.

[13] Why you ask many questions for me? (Japanese L1; Wei, 1995)

[14] Wait. I first fill water in glass. Wait.

[15] He busy. He not help my homework.

[16] Parent provide money to me.

(Japanese L1; Wei, 1996a, p. 422)

[17] Will you give your phone number?

(Japanese L1; Wei, 2003, p. 66)

In [12], 'wait' takes 'you' as its object and directly assigns the THEME to it. In English, 'wait' is an intransitive verb and cannot take an object. The proposition 'for' is required to introduce an object and assigns the thematic role to it (e.g., 'wait for you'). Such an error may be caused by the learner' transfer of the predicate-argument structure of the Japanese equivalent verb 'matsu (wait)', which is a transitive verb and can take its internal object. In [13], 'me' is assigned the GOAL by the preposition 'for', structurally subordinate to the verb internal object 'many questions', which is assigned the THEME. Such a predicate-argument structure reflects the Japanese counterpart verb 'suru (ask)' which projects the GOAL as a postpositional object with the postposition 'ni', rather than the verb internal object indicated by the particle 'o'. In [14], 'fill' assigns the THEME to 'water', rather than assigning the PATIENT to 'glass' and introducing the THEME by the preposition 'with', and 'glass is assigned the LOCATION by the preposition 'in', rather than the PATIENT as required in English (e.g., 'fill the class with water'). In [15], the preposition 'with' as required in English does not appear to assign the THEME to 'my homework'. This error may be caused by the predicate-argument structure of the Japanese equivalent verb 'tasukeru (help)', which can assign the thematic role directly to the object. In [16], 'provide' assigns the THEME, rather than the RECIPIENT, to the object, violating the predicate-argument structure of the verb in English, where the THEME is assigned by the preposition 'with' (e.g., 'provide me with money'). Such an error reflects the predicate-argument of the Japanese equivalent verb 'teikyoo (provide)', which assigns the THEME directly to its internal object. In [17], the speaker employs the Japanese predicate-argument structure of the verb 'give' rather than the English indirect object dative or double objects dative construction. While in Japanese, the equivalent verb 'kureru (give)' does not require an explicit RECIPIENT or GOAL, in English both the THEME and the RECIPIENT must appear either in the indirect object dative construction (e.g., 'Will you give your phone number (THEME) to me (RECIPIENT)?')or in the double object dative construction (e.g., 'Will you give me (RECIPIENT) your phone number (THEME)?'). 
[18] densha o totte gakkoo e iku. train in PART/OBJ take school to go

"(I) take the train to go to school."

[19] haha wa shopping iku. mother PART/TOP shopping go "(My) mother goes shopping."

[20] gozenchuu kare o yonda. in the morning him PART/OBJ called

"(I) called him in the morning."

(English L1; Wei, 2003, p. 69)

In [18], the speaker produces the Japanese verb 'toru/tote (take)' influenced by the predicate-argument structure of the equivalent verb in English, where the means of transportation 'densha (train)' is introduced as the direct object and is assigned the THEME. However, in Japanese, 'densha' must be introduced as the LOCATION in a prepositional phrase by the verb 'noru/note (take)' To follow the Japanese predicate-argument structure, the same concept should be realized as below.

densha ni note gakkooo e iku.

train in take school to go

"(I) take the train to go to school.'

In [19], the speaker translates the English verb phrase 'go shopping' into Japanese, violating the Japanese predicate-argument structure of the verb 'iku (go)'. While in English 'shopping' is assigned the GOAL by the verb 'go', in Japanese 'shoppinggu (shopping)' is assigned the GOAL by the preposition 'ni'. To follow the Japanese predicate-argument structure, the same concept should be realized as below.

haha wa shoppinggu ni iku.

mother OART/TOP shopping for go

"(My) mother foes shopping."

In [20], the speaker produces the Japanese verb 'yoru/yonda (call)' influenced by the predicate-argument structure of the equivalent verb in English, where the semantic features of 'communicate with by telephone' are conflated in the verb 'call'. Thus, in English the object of 'call' is assigned the RECIPIENT. However, in Japanese the RECIPIENT must be introduced by a preposition and the phone-call itself must be introduced as the THEME by a specific verb such as 'kakeru' or 'suru'. To follow the Japanese predicate-argument structure, the same concept should be realized as below.

gozenshuu kare ni denwa o kaketa (or denwa o shita).

in the morning him in phone PART/OBJ called (or: hone PART/OBJ did)

"(I) called him in the morning."

The above instances reveal that the predicate-argument structure, as one of the subsystems, of the TL abstract lexical structure is not available to early-stage learners. Although learners' target is always and should be the L2 abstract lexical structure, in this case, the L2 predicate-argument structure as one of its subsystem is predictably a composite of structures from multiple sources, including not only L1 lexical-conceptual structures or intended ones in the L2 but also L1 predicate-argument structures and/or incompletely acquired ones in the L2.

\subsection{Transfer of L1 Morphological Realization Patterns in IL Construction}

The third level or subsystem of abstract lexical structure is called 'morphological realization patterns', which are defined as surface devices for word order, case, agreement, inflectional morphology for tense/aspect/voice/mood marking, and other language-specific surface morphological requirements.

As revealed in the researches by Aaronson and Ferres (1987), Long (1997), Fuller (1999), Wei (2004, 2006a, 2018), Liu (2015, 2019), and Wei and Liu (2017) among others, if learners are not knowledgeable enough about the lemmas about the language-specific morphological realization patterns as contained in abstract lexical structure, they may turn back on their L1 morphological structure, resulting in the transfer of L1 morphological realization patterns in IL construction. Again, to completely acquire the abstract lexical structure includes the lemmas underlying the $\mathrm{L} 2$ morphological realization patterns.

[21] In Japan student English junior high school start.

[22] I everyday by bus go to school.

[23] Tomorrow to New York we'll go with some friends.

[24] Sorry. Only little English know.

(Japanese L1; Wei, 1995) 
In [21]-24], the speakers turn to the Japanese basic Subject - Object -Verb (SOV) word order, where any constituent, whether it is the object of the verb as in [21] and [24] or a prepositional phrase as in [22] and [23], is placed before the verb.

[25] I English ... speak not well.

[26] I everyday use bike. Taxi? No. I live not far.

[27] EPI teacher help me English speak.

[28] I go to party with friend tomorrow.

(Japanese L1; Wei, 1996a, p. 421)

In [25] and [26] the speakers fail to produce the auxiliary verb for negation. Such an error seems to be influenced by the Japanese morphological realization patterns, where the particle 'not' for negation is not placed with verbs but with other items like adverbs and adjectives. In [27], the article for the subject noun 'EPI teacher' is missing, and the verb 'help' is not inflected for the third person singular. In [29], the noun 'friend' is not inflected for plural, the article for 'party' is missing, and the verb 'go' is not marked for the grammatical concept of future tense.

[29] watashitachi wa shigoto ni iku mainichi. we PART/TOP work to go everyday

"We go to work everyday."

[30] watashi wa moou kakiowatta watashino repooto.

I PART/TOP already finished my paper

"I already finished my paper."

(English L1; Wei, 2003, p. 69)

In [29], although the sentence basically follows the Japanese verb final order, the adverbial of time 'mainichi (every day)' is placed in the sentence final position, which is allowed in English, but not in Japanese. In [30], the sentence closely follows the typical English word order where the object follows the predicate verb.

The above instances reveal that L1 morphological realization patterns, as one of the subsystems of abstract lexical structure, may also be transferred in IL construction in early stages of L2 learning.

\section{Role of Language Transfer in Second Language Acquisition}

Although the earlier theoretical assumptions about the nature and role of language transfer are discredited, language transfer is still recognized as one of the most important factors which shape the developing linguistic system of IL. The notion of language transfer has been revived and remains fundamental in SLA research. Although there have been many debates over the relationship between universal principles and language transfer, any research in SLA must involve the study of transition from learners' L1 to their targeted L2 (Selinker, 1972; Selinker et al., 1975; Corder, 1983). Researchers have also found that early L2 learners may transfer certain properties of their L1 into their current IL, but they do not do so blindly. Thus, it comes necessary to discover what L1 properties can be expected to transfer or incorporate naturally into their developing linguistic systems of IL.

Drawing on and departing from most observational and/or descriptive models of language transfer, the BLAM attempts to explore the nature and activity of the bilingual mental lexicon in the process of SLA and redefines the role of language transfer by considering two important implications. The first is the implication that any analysis of IL surface forms will remain observational and superficial if it fails to relate what is observed to what is going on in learners' mental activity. This is because the phenomenon of language transfer reflects learners' immature processing routines driven by their bilingual mentality, which must have an important role to play in their IL production and development. The second is the implication that language transfer should be seen primarily as learners' production strategies rather than an automatic or unconscious process. This view follows the cognitive paradigm that characterizes language transfer as learners' problem-solving procedure or learning strategy by utilizing their L1 knowledge to solve a learning or spontaneous communication problem (Kellerman, 1977; Jordens, 1977; Sharwood Smith, 1979; VanPatten, 1984a, 1984b, 1995; Jake, 1998; Wei, 2000a, 2000b).

The BLAM views learners' production or formalization of a given L2 as affected not only by their L1 but also by the current state of their IL. The implication of this view is that there is no need to redefine the term 'language transfer' in order to interpret IL data in SLA research. Language transfer is now seen to take place proactively or retroactively. In other words, old language knowledge (i.e., L1 knowledge) may influence new knowledge (i.e., L2 knowledge), and new knowledge may influence old knowledge. As assumed in cognitive learning theory, existing knowledge plays a role in internalizing any new information (McLaughlin, 1978; Sharwood Smith, 1979, 1986; McDonough, 1981; Faerch and Kasper, 1986; Jake, 1998; Wei 2015). The BLAM also views language transfer as an accommodation process (i.e., a natural developmental process) to successful SLA, which can predict the directions of IL development toward the TL. 


\section{Conclusion}

This study applies the BLAM to the exploration of sources of language transfer at a rather abstract level of speech production process. This study is abstract in the sense that it goes beyond the surface observation and description of language transfer by investigating the nature and activity of the bilingual mental lexicon during IL production.

As assumed in the BLAM, the bilingual mental lexicon contains language-specific lemmas underlying particular lexemes, and such language-specific lemmas are in contact in L2 learning. Different from most previous studies, this study discusses the phenomena of language transfer in terms of lemma transfer in three subsystems of abstract lexical structure: lexical-conceptual structure, predicate-argument structure, and morphological realization patterns. This study offers three implications for understanding the nature and role of language transfer in L2 learning and IL development.

1. Language transfer reflects that learners' L1 must pay a role in influencing the developing linguistic system of IL. Thus, the role of language transfer should be investigated in terms of its synchronic procedure in speech production (i.e., for spontaneous communication or immediate speech production) and its diachronic procedure in IL development (i.e., for predictable and systematic movement along the IL continuum).In other words, language transfer can be viewed as learners' learning strategy or problem-solving skill by turning back on certain L1 lemmas for the equivalent L2 lexical-conceptual structure, predicate-argument structure, and/or morphological realizations.

2. All instances of language transfer should be viewed as learners' activation of their L1 knowledge at several different but related levels of abstract lexical structure in IL production. Such an activation of L1 knowledge unavoidably occurs because learners' incomplete knowledge of particular L2 lexical items can be understood as their incomplete knowledge of particular lemma specifications for each of the subsystems of the abstract lexical structure in the L2. Thus, any successfully SLA must involve the full acquisition of language-specific lemmas for all L2 lexical items.

3. The notion of 'language transfer' should be related to the notion of interaction between learners' L1 knowledge and L2 knowledge being learned. The BLAM predicts that sufficient acquisition of language-specific lemma specifications for the L2 abstract lexical structure becomes absolutely necessary for successful SLA. To make this happen, language-specific lemmas in the bilingual mental lexicon must be clearly separated during the process of L2 learning. This is because successful SLA involves language transfer as an unavoidable and transitional procedure, but language-specific lexicalization and grammaticalization patterns must be learned as they are. Otherwise, native-like L2 knowledge and proficiency would be impossible.

\section{References}

Barsalou, L. (2003). Situated simulation in the human conceptual system. Language and Cognitive Processes, 18, 513-562.

Bickerton, D. (1981). From concepts to lexical items. Cognition, 41, 23-60.

Bierwisch, M., \& Schreuder, R. (1992). From concepts to lexical items. Cognition, 41, $23-60$.

Biskup, D. (1992). L1 influence on learners' rendering of English collocations: A Polish/German empirical study. In P. J. L. Arnaud \& H. Béjoint (Eds.), Vocabulary and applied linguistics (pp. 85-93). London: Macmillan.

Bley-Vroman, R. (1989). What is the logical problem of second language learning. In S. M. Gass \& J. Schachter (Eds.), Linguistic perspectives on second language acquisition (pp. 41-68). Cambridge: Cambridge University Press.

Bock, K., \& Levelt, W. J. M. (1994). Language production: Grammatical encoding. In M. A. Gernsbacher (Ed.), Handbook of psycholinguistics (pp. 945-984). New York: Academic Press.

Cazden, C. B. (1972). Child language and education. New York: Holt, Rinehart and Winston.

Chomsky, N. (1965). Aspects of the theory of syntax. Cambridge, MA: MIT Press.

Chomsky, N. (1980). On cognitive structures and their development: A reply to Piaget. In M. Piatelli-Palmarini (Ed.), Language and Learning: Debate between Jean Piaget and Noam Chomsky (pp. 35-54). London: Routledge and Kegan Paul.

Chomsky, N. (1981). Principles and parameters in syntactic theory. In N. Hornstein \& D. Lightfoot (Eds.), Explanations in linguistics: The logical problem of language acquisition (pp. 32-75). London: Longman.

Cook, V. J. (1985). Universal grammar and second language acquisition. Applied Linguistics, 6(1), 2-18.

Cook, V. J. (1988). Chomsky's universal grammar: An introduction. Oxford: Basil Blackwell.

Cook, V. J. (1991). The poverty-of-the-stimulus argument and multicompetence. Second Language Research, 7, 103-117.

Corder, S. P. (1967). The significance of learners' errors. International Review of Applied Linguistics, 5, 161-170.

Corder, S. P. (1971). Idiosyncratic dialects and error analysis. International Review of Applied Linguistics, 9, 149159.

Corder, S. P. (1981). Error analysis and interlanguage. Oxford: Oxford University Press. 
Corder, S. P. (1983). A role of the mother tongue. In S. M. Gass \& L. Selinker (Eds.), Language transfer in language learning (pp. 85-97). Rowley, MA: Newbury House.

Costa, A. (2005). Lexical access in bilingual production. In J. F. Kroll \& A. M. B. de Groot (Eds.), Handbook of Bilingualism: Psycholinguistic Approaches (pp. 308-325). Oxford: Oxford University Press.

Dagut, M., \& Laufer, B. (1985). Avoidance of phrasal verbs: A case for contrastive analysis. Studies in Second Language Acquisition, 7, 73-79.

Dewaele, J-M. (1998). Lexical inventions: French interlanguage as L2 versus L3. Applied Linguistics, 19, 471-490.

Dušková, L. (1984). Similarity: An aid or hindrance in foreign language learning. Folia Linguistica, 18, 103-115.

Ellis, R. (1994). The study of second language acquisition. Oxford: Oxford University Press.

Færch, C., \& Kasper, G. (1986). Cognitive dimensions of language transfer. In E. Kellerman \& M. Sharwood Smith (Eds.), Crosslinguistic influence in second language acquisition (pp. 49-65). Elmsford, NY: Pergamon Press.

Flynn, S. (1987). A parameter-setting model of L2 acquisition. Dordrecht: Reidel.

Fuller, J. M. (1999). The role of English in Pennsylvania German development: Best supporting actress? American Speech, 74(1), 38-55.

Gass, S. M., \& Selinker, L. (1994). Second language acquisition: An introductory course. Hillsdale, NJ: Lawrence Erlbaum.

Hyltenstam, K. (1977). Implicational patterns in interlanguage: On the categorical status of functional elements. Linguistics, 32, 271-298.

Jackendoff, R. (1990). Semantic structures. Cambridge, MA: MIT Press.

Jackendoff, R. (1991). Parts and boundaries. Cognition, 41, 9-45.

Jake, J. L. (1994). Intrasentential codeswitching and pronouns: On the categorical status of functional elements. Linguistics, 32, 271-298.

Jake, J. L. (1998). Constructing interlanguage: Building a composite matrix language. Linguistics, 36, 333-382.

Jarvis, S. (2003). Probing the effects of the L2 on the L1: A case study. In V. Cook (Ed.), Effects of the second language on the first (pp. 81-102). Clevedon: Multilingual Matters.

Jarvis, S. (2009). Lexical transfer. In A. Pavlenko (Ed.), The bilingual mental lexicon: Interdisciplinary approaches (pp. 99-124). Bristol: Multilingual Matters.

Jiang, N. (2000). Lexical representation and development in a second language. Applied Linguistics, 21(1), 47-77.

Jordens, P. (1977). Roles grammatical intuitions and strategies in foreign language learning. Interlanguage Studies Bulletin, 2, 5-76.

Kellerman, E. (1977). Towards a characterization of the strategies of transfer in second language learning. Interlanguage Studies Bulletin, 2, 58-145.

Kellerman, E. (1987). Aspects of transferability in second language acquisition. Unpublished doctoral dissertation, University of Nijmegen.

Klein, W., \& Perdue, C. (1989). The learner's problem of arranging words. In B. MacWhinney \& E. Bates (Eds.), The crosslinguistic study of sentence processing (pp. 292-327). Cambridge: Cambridge University Press.

Kleinmann, H. (1977). Avoidance behavior in adult second language acquisition. Language Learning, 27, 93-107.

Krashen, S. D. (1982). Principles and practice in second language acquisition. Oxford: Pergamon Press.

Krashen, S. D. (1985). The input hypothesis: Issues and implications. New York: Longman.

Lado, R. (1957). Linguistics across cultures: Applied linguistics for language teachers. Ann Arbor, ML: University of Michigan Press.

Lennon, P. (1991). Error and the very advanced learner. IRAL, 29, 31-44.

Levelt, W. J. M. (1989). Speaking: From intention to articulation. Cambridge, MA: MIT Press.

Levin, B., \& Pinker, S. (1991). Introduction to special issue of Cognition on lexical and conceptual semantics. Cognition, 41, 1-7.

Liu, X. (2012). Lexical borrowing: A case study of the language contact phenomenon in Japan and China. Japan Studies Review, 16, 17-36.

Liu, X. (2015). Language transfer in learning Japanese and interlanguage development. US-China Foreign Language, 13(4), 236-244.

Liu, X. (2019). The light verb "suru" in Japanese lexical-conceptual structure and sources of learning difficulty. Studies in Linguistics and Literature, 3(4), 352-362.

MacWhinney, B. (1987). The competition model. In B. MacWhinney (Ed.), Mechanisms of language acquisition (pp. 249-308). Hillside, NJ: Lawrence Erlbaum Associates.

MacWhinney, B. (1989). Competition and lexical categorization. In R. Corrigan, F. Eckman, \& M. Noonan (Eds.), Linguistic categorization (pp. 195-242). New York: John Benjamins.

MacWhinney, B. (1992). Transfer and competition in second language learning. In R. J. Harris (Ed.), Cognitive processing in bilinguals (pp. 371-390). Amsterdam: Elsevier.

MacWhinney, B. (1996). Language specific prediction in foreign language acquisition. Language Testing, 12, 292320. 
MacWhinney, B. (1997). Second language acquisition and the competition model. In A. M. B. Groot \& J. F. Kroll (Eds.), Tutorials in bilingualism: Psycholinguistic perspectives (pp. 113-142). Mahwah, NJ: Erlbaum.

Malt, B. C., Sloman, S. A., \& Gennari, S. (2003). Universality and language specificity in object naming. Journal of Memory and Language, 29, 20-42.

McNeill, D. (1966). Developmental psycholinguistics. In F. Smith \& G. Miller (Eds.), The genesis of language: A psycholinguistic approach (pp. 15-84). Cambridge, MA: MIT Press.

Myers-Scotton, C., \& Jake, J. L. (1994). Embedded language islands in intrasentential codeswitching: Variation and compromise at two linguistic levels. Poster presented at the Annual Meeting of New Ways of Analyzing Variation, Stanford University, CA.

Myers-Scotton, C., \& Jake, J. L. (1995). Matching lemmas in a bilingual language competence and production model: Evidence from intrasentential code switching. Linguistics, 33(5), 981-1024.

Nemser, W. (1971). Approximative systems of foreign language learners. International Review of Applied Linguistics, 9, 115-123.

Pavlenko, A. (1997). Bilingualism and cognition. Unpublished doctoral dissertation, Cornell University, NY.

Pavlenko, A. (2003). Eyewitness memory in late bilinguals: Evidence for discursive relativity. International Journal of Bilingualism, 7(3), 257-281.

Pavlenko, A. (2009). Conceptual representation in the bilingual lexicon and second language vocabulary learning. In A. Pavlenko (Ed.), The bilingual mental lexicon: Interdisciplinary approaches (pp. 125-160). Bristol: Multilingual Matters.

Pinker, S. (1984). Language learnability and language development. Cambridge, MA: Harvard University Press.

Pinker, S. (1989a). Learnability and cognition. Cambridge, MA: MIT Press.

Pinker, S. (1989b). Resolving a learnability paradox in the acquisition of the verb lexicon. In M. L. Rice \& R. L. Schiefelbusch (Eds.), The teachability of language (pp. 12-61). Baltimore, MD: Brushwood Graphics.

Richards, J. C. (Ed.). (1974). Error analysis: Perspectives on second language acquisition. London: Longman.

Schachter, J. (1974). An error in error analysis. Language Learning, 24, 205-214.

Schachter, J. (1988). Second language acquisition and its relationship to universal grammar. Applied Linguistics, 9, 219-235.

Selinker, L. (1972). Interlanguage. International Review of Applied Linguistics, 10, $209-230$.

Selinker, L., Swain, M., \& Dumas, G. (1975). The interlanguage hypothesis extended to children. Language Learning, 25, 345-361.

Sharwood Smith, M. (1979). Strategies, language transfer and the simulation of the language learner's mental operations. Language Learning, 29, 345-361.

Sharwood Smith, M. (1986). The competence/control model, crosslinguistic influence and the creation of new grammars. In E. Kellerman \& M. Sharwood Smith (Eds.), Crosslinguistic influence in second language acquisition (pp. 10-20), Elmsford, NY: Pergamon Press.

Stepanova Sachs, O., \& Coley, J. (2006). Envy and jealousy in Russian and English: Labeling and conceptualization of emotions by monolinguals and bilinguals. In A. Pavlenko (Ed.), Bilingual minds: Emotional experience, expression, and representation (pp. 208-231). Clevedon: Multilingual Matters.

Talmy, L. (1985). Lexicalization patterns: Semantic structure in lexical forms. In T. Shopen (Ed.), Language typology and syntactic description (Vol. 3, pp. 57-149). Cambridge: Cambridge University Press.

MacWhinney, B. (1987). The competition model. In B. MacWhinney (Ed.), Mechanisms of language acquisition (pp. 249-308). Hillside, NJ: Lawrence Erlbaum Associates.

McLaughlin, B. (1978). The monitor model: Some methodological considerations. Language Learning, 28, 309332.

VanPatten, B. (1984a). Processing strategies and morpheme acquisition. In F. R. Eckman, L. H. Bell, \& D. Nelson (Eds.), Universals of second language acquisition (pp. 88-98). Rowley, MA: Newbury House.

VanPatten, B. (1984b). Learners' comprehension of clitic pronouns: More evidence for a word order strategy. Hispanic Linguistics, 1, 57-67.

VanPatten, B. (1995). Cognitive aspects of input processing in second-language-acquisition. In P. Hashemipour, R. Maldonado, \& M. van Naerssen (Eds.), Studies in language learning and Spanish linguistics in honor of Tracy D. Terrel (pp. 170-183). New York: McGraw-Hill.

Wardhaugh, R. (1970). The contrastive analysis hypothesis. TESOL Quarterly, 4, 123-130.

Wei, L. (1995). Unpublished Chinese and Japanese learners' interlanguage data.

Wei, L. (1996a). Organizing principles behind codeswitching and interlanguage development in early adult second language acquisition. In J. Arnold, R. Blake, B. Davidson, S. Schwenter, \& J. Solomon (Eds.), Sociolinguistic Variation, Data, Theory, and Analysis (pp. 417-431). Stanford, CA: CSLI Publications.

Wei, L. (1996b). Variation in the acquisition of morpheme types in the interlanguage of Chinese and Japanese learners of English as a second language. Unpublished doctoral dissertation, University of South Carolina, Columbia, SC. 
Wei, L. (1998). Complex lexical structure and morpheme acquisition in interlanguage development. In M. C. Gruber, D. Higgins, K. S. Olson, \& T. Wysocki (Eds.), CLS 34, Part 2: The status of constraints, the acquisition of spoken language, acquisition and the lexicon(pp. 535-545). Chicago Linguistic Society, University of Chicago, IL.

Wei, L. (2000a). Unequal election of morphemes in adult second language acquisition. Applied Linguistics, 2, 106140.

Wei, L. (2000b). Types of morphemes and their implications for second language morpheme acquisition. International Journal of Bilingualism, 4(1), 29-43.

Wei, L. (2001). The multilingual mental lexicon: Language separation/activation in trilinguals. Papers Selected from the Second International Conference on Third Language Acquisition and Trilingualism: Interactive $C D-R O M$ (pp. 13-15). Fryske Akademy.

Wei, L. (2002). The bilingual mental lexicon and speech production process. Brain and Language, 81, 691-707.

Wei, L. (2003). Activation of lemmas in the multilingual mental lexicon and transfer in third language learning. In J. Cenoz, B. Hufeisen, \& U. Jessner (Eds.), The multilingual lexicon (pp. 57-70). Dordrecht: Kluwer Academic Publishers.

Wei, L. (2004). Second language production of English dative constructions: A lexicon-driven approach to target syntax. The Proceedings of the Sixth International Symposium on Applied Linguistics and Language Teaching (pp. 621-634). The University of Northern Iowa.

Wei, L. (2006a). The multilingual mental lexicon and lemma transfer in third language learning. International Journal of Multilingualism, 3(2), 88-104.

Wei, L. (2006b). Intrasentential codeswitching as conceptual projection of lemmas in the bilingual mental lexicon. Journal of Cognitive Science, 7(2), 149-178.

Wei, L. (2015). Interlanguage: The abstract level in language acquisition. New York: The Edwin Mellen Press.

Wei, L. (2018). Abstract lexical structure in second language learning. Studies in Linguistics and Literature, 2(3), 223-243.

Wei, L., \& Liu, X. (2017). The bilingualmental lexicon and language transfer in second language learning. International Journal of Language and Linguistics, 4(4), 11-23.

Weinreich, U. (1953). Languages in contact. New York: Linguistic Circle of New York.

White, L. (1985a). The 'pro-drop' parameter in adult second language acquisition. Language Learning, 35, 47-62.

White, L. (1985b). The acquisition of parameterized grammars: Subjacency in second language acquisition. Second Language Research, 1(1), 1-17.

White, L. (1987). Markedness and second language acquisition: The question of transfer. Studies in Second Language Acquisition, 9, 261-285.

White, L. (1990). The verb-movement parameter in second language acquisition. Language Acquisition, 1, 337360.

Zobl, H. (1980a). The formal and developmental selectivity of L1 influence on L2 acquisition. Language Learning, 30, 43-57.

Zobl. H. (1980b). Developmental and transfer errors: Their common bases and (possibly) differential effects on subsequent learning. TESOL Quarterly, 14, 469-479.

Zughoul, M. R. (1991). Lexical choice: Towards writing problematic word lists. IRAL, 29, 45-59. 